\title{
FORMAR LEITORES NA ESCOLA: O PROJETO PEDAGÓGICO, A BIBLIOTECA ESCOLAR E A MEDIAÇÃO
}

\author{
FORMAR LECTORES EN LA ESCUELA: EL \\ PROYECTO PEDAGÓGICO DE AULA, LA \\ BIBLIOTECA Y LA MEDIACIÓN
}

\begin{abstract}
Rovilson José da Silva - rovilson@uel.br Doutor em Educação pela Universidade Estadual Paulista Júlio de Mesquita Filho (UNESP/Marília). Professor do Departamento de Educação da Universidade Estdual de Londrina (UEL).
\end{abstract}

\section{RESUMO}

Introdução: Aborda a formação de leitores na escola de Anos Iniciais do ensino fundamental e propõe a integração entre o projeto pedagógico escolar, o grupo docente, as práticas de leitura e a biblioteca da escola.

Objetivo: Analisar as premissas básicas para se formar leitores na escola.

Metodologia: Pesquisa bibliográfica, com base em revisão de literatura acerca do assunto.

Resultados: São apresentados elementos iniciais que podem servir de reflexão e estruturação de projeto para formação de leitores em qualquer escola.

Conclusões: Formar leitores na escola consiste numa conjuntura de procedimentos e ações pedagógicas, realizados em concomitância, entre o uso orientado e livre da biblioteca, o empréstimo de livros e momentos de ouvir histórias e conversar sobre elas.

Palavras-chave: Formação de leitores nos anos iniciais. Mediador de leitura. Biblioteca escolar.

\section{INTRODUÇÃO}

Não existe poção milagrosa para formar leitores na escola, mas é necessário planejamento que estruture e apoie o trabalho em todas as 
instâncias, ou seja, direção, coordenação pedagógica e professores articulando ações a fim de que os alunos cheguem à leitura. Isso parece simples, mas a escola ainda não tem conseguido unir essas forças em prol da formação de leitores, pois muitas vezes os encaminhamentos dados à leitura no âmbito escolar chegam a ser conflitantes entre os próprios pares.

Parece impossível aprender a nadar sem ter água, piscina ou rio, mas o tratamento que a leitura tem recebido na escola é como se isso fosse possível. Se para nadar é preciso piscina e água, para aprender a ler é preciso que haja livros, biblioteca e mediação de leitura, entretanto, ainda permanece na escola a ideia de formar leitores apenas com o discurso aos alunos de que a leitura é importante, que ela faz bem ao sujeito, auxilia no seu desenvolvimento e ainda pode ser uma fonte de prazer, de lazer.

Embora essas reafirmações façam parte do senso comum no discurso de professores, na escola falta espaço para a reflexão acerca de como a leitura tem sido mediada em seu âmbito e há muito a se indagar a esse respeito. Por isso, cabe à equipe docente perguntar-se: qual é o incentivo à leitura que a escola oferece aos alunos? Qual é o acesso dos alunos à biblioteca? Ao seu acervo? Há momento para a troca de ideias sobre o que foi lido?

Portanto, discutimos as premissas básicas para mediar a leitura na escola e, assim, iniciar a formação contínua de leitor, dos Anos Iniciais à universidade, centralizando-o em três aspectos, que julgamos primordiais no processo de formação de leitores na escola, a saber: projeto pedagógico, biblioteca escolar e mediação.

\section{O PROJETO PEDAGÓGICO DA ESCOLA E A FORMAÇÃO DE LEITORES}

A escola tem como meta levar o aluno à leitura, embora dificilmente haja discussão ampla entre os pares a respeito desse 
assunto na construção de seu plano educacional. Nesse sentido, para formar leitor na escola, antes de tudo, é necessário que o projeto pedagógico que dá sustentação ao ensino escolar tenha objetivos explícitos em relação à leitura em seu âmbito, ou seja, de modo que a equipe pedagógica, previamente, tenha estabelecido quais serão as estratégias a serem utilizadas para atingir a meta almejada.

Uma das prerrogativas, nesse caso, é que a equipe de ensino deve questionar-se o porquê da leitura na escola, pois é a partir de discussões a respeito do conceito de leitura de cada um que se pode chegar à concepção do que a equipe docente almeja para promover a leitura na escola. Esse processo pode gerar conflitos momentâneos, uma vez que a exposição de pontos de vistas sobre a leitura trará à tona conceitos divergentes sobre a mediação de leitura na escola, frustrações pessoais em relação a ela, entretanto, com o diálogo entre os pares, pode-se chegar ao consenso mínimo para se iniciar o trabalho, visto que há que se definirem pontos em comum para o andamento dos trabalhos.

Assim, num primeiro momento, cabe à equipe de ensino refletir acerca de sua relação com a leitura, tornando evidente ao grupo como a concebe. Para isso é preciso indagar-se:

- Qual é minha relação pessoal e profissional com a leitura?

- O que significa leitura para mim?

- Qual é a importância que ela tem para mim: discurso? Prática?

- Como eu conduzo a leitura na escola?

- Que estratégias eu utilizo para levar a leitura aos alunos?

Essas e outras questões que estão no âmbito dessa temática, auxiliarão para que se chegue à concepção que será utilizada pela escola para desenvolver o seu projeto de formação de leitores, onde a leitura esteja além de uma mera reprodução mecânica de atividades. Conforme Colomer e Camps (2002, p. 31-32): de signos gráficos, é antes de tudo um ato de raciocínio, já 
que se trata de saber orientar uma série de raciocínios no sentido da construção de uma interpretação da mensagem escrita a partir da informação proporcionada pelo texto e pelos conhecimentos do leitor [...].

Atuando como professores, muitas vezes, em diversas situações, dentro e fora da escola, tanto para a equipe pedagógica quanto para pais e ou comunidade externa temos de responder à questão "Por que ler? Portanto, a resposta não deve ser vazia de significado, principalmente para o próprio professor, que deve aliar sua vivência como leitor à fundamentação teórica exigida para mediar essa prática humanizadora, de conhecimento de si e do mundo, pois "[...] lê-se para entender o mundo, para viver melhor" (LAJOLO, 1994, p. 7). Portanto, cada livro lido oferece ao leitor a possibilidade de se encontrar com pessoas diferentes, como afirma Bloom (2001, p. 25):

Lemos, intensamente, por várias razões, a maioria das quais conhecidas: porque, na vida real, não temos condições de "conhecer" tantas pessoas, com tanta intimidade; porque precisamos nos conhecer melhor; porque necessitamos de conhecimento, não apenas de terceiros e de nós mesmos, mas das coisas da vida.

A leitura, nesse contexto, tem valor coletivo e individual, de modo que no ambiente escolar se torne elemento de formação individual do ser humano em construção social e intelectual, bem como instrumento pedagógico de apoio ao ensino, ao conhecimento, à arte e ao lazer. Lajolo (1986, p. 52) pondera acerca do tratamento a ser dado ao texto na escola:

O texto não é pretexto para nada. Ou melhor, não deve ser. Um texto existe apenas na medida em que se constitui ponto de encontro entre dois sujeitos: o que escreve e o que lê; escritor e leitor, reunidos pelo ato radicalmente solitário da leitura, contrapartida do igualmente solitário ato de escrita.

Assim, faz-se necessário discutir, em relação ao projeto pedagógico de formação de leitor, que "tipo" de leitura, de texto que a escola priorizará, ou melhor, como será o encaminhamento para a leitura literária e para a não literária. Como será o processo de mediação do texto em cada uma dessas vertentes, ou haveria apenas um único 
modelo para todos os tipos de textos? Ou, ainda, as estratégias de mediação serão diferentes para cada texto?

No caso do ensino nos Anos Iniciais, cuja faixa etária varia de 06 a 10 anos, oportuniza-se à criança o contato sistemático com obras de literatura infantojuvenil, pois nesse período de formação, essas obras contribuem para o amadurecimento psicológico da criança, auxilia-a a encontrar sentido na vida. Bettelheim (1985, p. 12) afirma:

[...] Com respeito a essa tarefa, nada mais é importante que o impacto dos pais e outros que cuidam da criança: em segundo lugar vem nossa herança cultural, quando transmitida à criança de maneira correta. Quando as crianças são novas, é a literatura que canaliza melhor esse tipo de informação (grifo nosso).

Portanto, cabe à escola proporcionar o encontro da criança com farto material para a leitura e, nesse contexto, não deve prescindir do texto literário, pois por meio dele, há o estímulo da imaginação, da fantasia e isso contribui para que a criança estruture seu mundo interior, que ela encontre respostas para seus dilemas que nem sempre são verbalizados para o adulto. Assim, será condição indispensável que a escola possua biblioteca e que ela dê oportunidade para que o aluno chegue à leitura.

\section{BIBLIOTECA ESCOLAR E A FORMAÇÃO DE LEITORES}

A leitura tornou-se para a civilização um dos elementos essenciais para a comunicação, para disseminação da informação e da cultura. Nesse contexto, a biblioteca evidenciou-se como a instituição representativa para guarda, manutenção e disseminação da informação e dos diversos suportes à leitura, portanto, é referência no projeto de formação de leitores.

O uso sistemático da biblioteca torna-se determinante para o desenvolvimento educacional em qualquer instância do ensino quer seja educação infantil, ensino básico ou ensino universitário. Por meio dela, o 
aluno encontra-se com o que já foi produzido cultural e cientificamente pela humanidade e, ao mesmo tempo, constrói seu conhecimento, sedimenta-o, torna-se capaz de produzir conhecimentos novos.

Se o aluno universitário chega à graduação sem maturidade leitora, isso quer dizer que no processo de formação de leitores, desde os Anos Iniciais, não houve continuidade nas ações de promoção da leitura e, dentre elas, destaca-se o uso da biblioteca escolar, que permanece invisível em vários níveis de ensino.

É histórica a dissociação entre sociedade e biblioteca em nosso país. Em geral, essa instituição está ausente nas escolas públicas. Além disso, nas últimas décadas, o governo federal perpetuou a política contínua de envio de livros à escola pública sem, no entanto, assegurar o espaço apropriado para a organização da biblioteca. Essa situação, pelo menos no aspecto legal, teve amparo com a promulgação da Lei № 12.244/2010, que regulamentou a universalização das bibliotecas escolares:

Art. $1^{0}$ As instituições de ensino públicas e privadas de todos os sistemas de ensino do País contarão com bibliotecas, nos termos desta Lei.

Art. $2^{-}$Para os fins desta Lei, considera-se biblioteca escolar a coleção de livros, materiais videográficos e documentos registrados em qualquer suporte destinados a consulta, pesquisa, estudo ou leitura.

Parágrafo único. Será obrigatório um acervo de livros na biblioteca de, no mínimo, um título para cada aluno matriculado, cabendo ao respectivo sistema de ensino determinar a ampliação deste acervo conforme sua realidade, bem como divulgar orientações de guarda, preservação, organização e funcionamento das bibliotecas escolares.

Art. $3^{\circ}$ Os sistemas de ensino do País deverão desenvolver esforços progressivos para que a universalização das bibliotecas escolares, nos termos previstos nesta Lei, seja efetivada num prazo máximo de dez anos, respeitada a profissão de Bibliotecário, disciplinada pelas Leis nos 4.084, de 30 de junho de 1962, e 9.674, de 25 de junho de 1998. (BRASIL, 2010).

Assim, a biblioteca escolar passa a ter caráter obrigatório e todas as escolas deverão se adequar até 2020 , entretanto, quase cinco anos se passaram e, até este momento, não há dados que indiquem 
investimentos para cumprir a Lei até o prazo estabelecido. Conforme constatou a pesquisa Avaliação das Bibliotecas Escolares no Brasil (ORGANIZAÇÃO DOS ESTADOS LIBERO-AMERICANOS, 2011), a presença da biblioteca ainda é rara nas escolas do Brasil, pois apenas 1/3 das 162.819 escolas do país, ou seja, 54.273 escolas informaram possuir biblioteca. Entretanto, é preciso ponderar que, embora essa seja a informação oferecida pelas escolas, a realidade pode dizer o contrário, pois muitas bibliotecas não têm estrutura mínima para, assim, serem denominadas. Em geral, as bibliotecas estão localizadas no pior espaço físico do prédio, pois grande parte de nossas escolas foi, e ainda o é, construída sem o espaço destinado a ela, isso gera o improviso espacial, a inadequação do espaço para as atividades que são inerentes a sua função na escola.

O improviso apresentado no espaço físico da biblioteca é sintoma do descaso social e educacional com essa instituição. A escola, microcosmo social, reproduz a relação desigual, descompromissada, esvaziada de sua função formativa das novas gerações que se apresentam ao ensino. Portanto, para formar leitores é prerrogativa que haja, no mínimo, livros e uma biblioteca na escola. Além disso, que a biblioteca e os livros estejam acessíveis ao aluno para que possa utilizar, manusear o acervo, conhecer o espaço, apropriar-se dele, sentir-se à vontade para explorá-lo da forma que the convier.

O contato do aluno com a biblioteca impulsiona a formação do futuro leitor, do pesquisador e poderá estimular sua aprendizagem e formação individual. Principalmente, rompe com a tradição de centralizar a aprendizagem do educando basicamente no professor. Conforme Macedo (2005, p. 174):

Ao professor e também ao bibliotecário caberá aproveitar todos os momentos para conduzir o aprendiz a praticar leituras nos diversos aspectos, cuidando do despertar das 
capacidades básicas e dos sentidos reais e figurados, do apurar a sensibilidade e a imaginação, para "ler a vida" ao seu derredor, para entender o social e o cultural; enfim, não só ficar sentado na carteira escolar ouvindo o professor.

$\mathrm{Na}$ rotina escolar, a biblioteca tem sido pouco explorada, tanto em relação ao espaço e acervo quanto à sua utilização pedagógica pela escola, são exceções os poucos professores que utilizam a biblioteca com seus alunos. Em relação ao espaço e ao acervo, em geral as bibliotecas são "gambiarras" educacionais, imagem do improviso, pois tudo o que é sobra, está velho ou foi trocado, vai para o espaço da biblioteca, tornando-a um espectro dentro da instituição (SILVA, 2010).

A aparência precária da biblioteca reflete o descaso pedagógico que existe com esta instituição dentro do ambiente escolar, tanto em relação ao aspecto pedagógico quanto ao físico - arquitetônico. Por isso, é possível constatar que a política de desenvolvimento de acervo, praticamente, não existe, tudo está condicionado ao acaso, pois os livros das bibliotecas escolares provêm, basicamente, de doação da comunidade e do envio de acervo pelo governo federal e, algumas vezes, do governo municipal. Diante disso, nem é preciso ser especialista para inferir que o acervo das bibliotecas escolares é desatualizado, desinteressante para os alunos.

Quanto à utilização pedagógica da biblioteca pela escola, os encaminhamentos são os mais inauditos, desde o uso como espaço punitivo até seu fechamento para transformá-la em depósito de material impresso, mobília ou equipamentos impróprios para o uso.

A esse respeito cabe ponderar: à escola não basta ter o espaço, importa que ele funcione em sua função precípua, ser biblioteca: com espaço, equipamentos e acervo adequados. Ainda são poucas as situações pedagógicas em que a biblioteca se transforme em espaço para o encontro de alunos, de professores, de troca, de busca. Nossa vivência escolar de muitos anos nos leva a afirmar que quase sempre a biblioteca é lugar de fuga, onde a palavra permanece presa nos livros, porque não existem propostas pedagógicas que estimulem o aluno a 
buscá-la. Nesse contexto, lembramos que cabe à biblioteca apresentarse como espaço organizado, que convide o aluno a ficar, a estar ali, a "perder" tempo lá dentro, a usar, manusear seus recursos.

O desafio à equipe de ensino (professor, bibliotecário, coordenador e diretor) é integrar a biblioteca ao processo educativo e, para que isso ocorra, urge que essa equipe discuta e encaminhe questões que estejam no seguinte âmbito:

- Que papel a biblioteca tem ocupado na escola?

- É satisfatória a relação escola - biblioteca? Quais são os fatores que emperram ou dinamizam essa relação?

- A biblioteca está integrada ao projeto pedagógico da escola?

- Quem utiliza a biblioteca? Quando?

- Todos têm acesso à biblioteca e ao seu acervo?

- Os alunos podem emprestar livros? Quando?

- Os professores utilizam a biblioteca com seus alunos?

- Há mediador (professor, bibliotecário ou técnico administrativo) na biblioteca para o atendimento de alunos e professores?

- Qual é o acervo que a biblioteca da escola possui? Atende ao que a escola precisa?

- Há política para compra de livros na escola? Qual a periodicidade da compra? Como os livros são selecionados para a compra?

- A rotina da biblioteca está clara para todos: alunos, professores e funcionários da escola?

- Qual seria a biblioteca mais adequada para a escola?

Questões como essas podem, inicialmente, instigar a discussão entre os professores acerca da integração da biblioteca ao projeto de ensino. Nessa fase é preciso oferecer espaço para que o profissional da educação traga à tona a experiência ou a inexperiência em trabalhar com a biblioteca e a leitura.

À medida que a equipe de ensino refletir sobre esta questão, melhor poderá ser sua compreensão da prática educacional a ser estruturada, de modo que a biblioteca esteja integrada ao projeto educacional da escola. Esse não é um processo fácil, mas se a escola se propuser a discutir abertamente e estabelecer as ações de curto, 
Formar leitores na escola: o projeto pedagógico, a biblioteca escolar e a mediação

médio e longo prazos, manterá a biblioteca aliada ao projeto de ensino e, com maior probabilidade, estará formando leitores.

\title{
4 MEDIAÇÃO DE LEITURA NA ESCOLA
}

Uma das premissas para mediar a leitura na escola é que o mediador seja leitor, pois dessa forma, ele terá mais claro para si mesmo, não apenas as metas pedagógicas, mas a sua própria experiência íntima com o texto poderá fazer diferença no processo de mediação. Nesse sentido, ele poderá ter maior facilidade para compreender as etapas pelas quais seus alunos passam no processo de se tornarem leitores, por fim, orientá-los para o encontro com a leitura.

$\mathrm{Na}$ escola, dentro e fora da sala de aula, importa prevalecer o ambiente de leitura de modo que haja sempre acervo disponível em diversos suportes, do papel ao digital, e que a comunidade escolar tenha espaço para a leitura, para trocar ideias a respeito do que foi lido, conciliando momentos cuja orientação advenha do grupo docente e, outros, com manifestações do grupo de alunos. Portanto, a escola deve oportunizar encontros de pura gratuidade com leitura, sem a preocupação com a cobrança pedagógica de se fazer alguma atividade, além da própria leitura.

Mediar a leitura na escola pressupõe, antes de tudo, possibilitar ao aluno encontrar seu caminho para formar-se leitor. Para Silva (2006, p. 76):

\begin{abstract}
Mediar a leitura na escola é estar alerta para que não reproduzamos as frases feitas, os preconceitos e ações que coíbam o fluir da leitura na escola, de modo que a criança seja respeitada nesse processo e tenha liberdade em seus primeiros passos rumo à leitura e que o professor seja o promotor desse encontro. No entanto, cabe ao professor ter subjacente a intencionalidade de levá-la a experimentar de pouco em pouco os diversos sabores da leitura.
\end{abstract}

No âmbito da mediação de leitura na escola há duas modalidades de textos que devem ser consideradas: os não literários e os literários. Para cada uma dessas vertentes, faz-se necessário estabelecer qual 
será o encaminhamento pedagógico a ser dado a cada modalidade, visto que ambas são necessárias à formação do leitor, mas cada qual requer mediação que não desvirtue sua essência, suas características artísticas ou informacionais.

Em relação ao texto não literário, importa esclarecer que são aqueles textos de cunho didático, informacional, textos científicos, anúncios, cibertexto/hipertexto da web, dicionários, enciclopédias e periódicos, entre outros. A função desses textos é informar de modo objetivo a respeito de algo. Esse é um texto bastante comum nas escolas, inclusive a abordagem que o professor dá a ele, em geral, está no âmbito da leitura e da busca de informação pelos alunos, para que respondam a questões cotidianas das disciplinas. A propósito, constata Silva (2010, p. 170-171):

Quanto aos textos não literários, a escola quase sempre os trata como se fossem simplesmente uma extensão do livro didático [...] O periódico é, muitas vezes, considerado supérfluo [...] não são atualizados, provêm de doações [...]. Quanto às leituras científicas, como enciclopédias, compêndios, livros que abordam assuntos variados [...] há pouco acervo na escola e nem sempre é usado, ora por desconhecimento, ora por não vê-lo como recurso pedagógico à disciplina estudada.

O fomento da leitura não literária, especialmente revistas e jornais atualizados, quer sejam eles impressos ou digitais, trazem a criança e o adolescente para a discussão de temas contemporâneos, que estão na mídia e que permeiam o cotidiano social. Dessa forma, a leitura torna-se próxima, rotineira e incorporada à vida do aluno. Assim, para mediar essa modalidade de textos, o professor (mediador) precisa ser leitor, ter intimidade com linguagem e temáticas, de modo a estruturar estratégias para que os alunos ampliem as fontes de leitura e, consequentemente, seu conhecimento.

Por outro lado, o texto literário é um texto artístico, que utiliza a linguagem figurada, a verossimilhança. É um texto que tem conteúdo plurissignificativo, de modo a criar atmosfera do belo, de dizer as coisas 

mediação

que estamos acostumados no cotidiano, organizadas de forma artística, o que cria no leitor a sensação de novidade, de algo peculiar, que the instiga a imaginação, a fantasia, enfim, estimula-lhe o prazer estético. Portanto, o trabalho com a narrativa literária, com a poesia e com 0 teatro deve ser mediado de modo distinto do texto não literário. O texto literário para Coelho (2000, p.16) justifica-se:

[...] por que de maneira mais abrangente do que quaisquer outros, eles estimulam o exercício da mente; a percepção do real em suas múltiplas significações; a consciência do eu em relação ao outro; a leitura do mundo em seus vários níveis e, principalmente, dinamizam o estudo e o conhecimento da língua, da expressão verbal significativa e consciente condição sine qua non para a plena realidade do ser.

Se um dos equívocos da escola é mediar a leitura literária da mesma forma que a não literária, então cabe a ela promover discussão, estudo e reflexão entre seus pares acerca dessa temática, a fim de estabelecer a concepção que o grupo possui para desenvolver 0 processo de mediação da literatura com os alunos, pois de acordo com Lajolo (1994, p. 7):

O que fazer com o ou do texto literário em sala de aula fundase, ou devia fundar-se, em uma concepção de literatura muitas vezes deixada de lado em discussões pedagógicas. Estas, de modo geral, afastam os problemas teóricos como irrelevantes ou elitistas diante da situação precária que, dizse, espera de o professor de literatura numa classe de jovens.

Mediar o texto literário pressupõe não torná-lo apenas um pretexto para atividades didáticas de língua portuguesa e ou demais disciplinas, pois quase sempre é isso que acontece na escola: a criança é levada a ler para fazer algo, para demonstrar o que leu, quer seja por meio de escrita ou de desenho.

Assim, a oralidade fica em segundo plano, as opiniões dos alunos a respeito do que foi lido e, principalmente, o silêncio não são respeitados. Dessa forma, necessitamos promover espaço para o silêncio dos leitores e suas leituras. Respeitar o silêncio é uma das 
maneiras de o aluno construir sua trajetória como leitor, instigá-lo a refletir e buscar as leituras que dialogam com seus predicamentos internos. Tornar-se leitor, nesse contexto, pressupõe que o aluno fará descobertas ora orientado pelo professor, ora por suas próprias preferências e contato sistemático com as obras e com a biblioteca da escola.

Há parâmetros que a escola de Anos Iniciais deve estabelecer para mediar a leitura, que podem ser discutidos a partir de indagações que orbitam em torno de:

- Quais textos serão priorizados nos anos iniciais?

- Como selecionar os textos para que atendam aos diferentes níveis cognitivos dos alunos?

- Como dosar a leitura de acordo com a idade da criança, mas sem tolher a liberdade do pequeno leitor em ousar, utilizar novidades, fontes distintas daquelas oferecidas para sua faixa etária, por exemplo?

Nesse processo reflexivo acerca do mediar a leitura na escola, a equipe de ensino deverá eleger as estratégias pedagógicas que serão utilizadas para promover a leitura, pois nos Anos Iniciais será necessário que o aluno tenha contato sistemático com a leitura, tanto de modo orientado pelo professor quanto de forma espontânea, além do uso da biblioteca, da realização da Hora do Conto e do papel exercido pelo mediador nesse contexto.

Em relação ao uso da biblioteca, todo aluno matriculado na escola tem o direito de acesso a atividades curriculares realizadas na, e em parceria, com a biblioteca. O empréstimo diário de livros é uma das estratégias para sedimentar o contato sistemático dos alunos com a leitura. Portanto, além do uso orientado da biblioteca durante as aulas, faz-se necessário que os alunos possam buscá-la espontaneamente e, assim, selecionar obras que lhes apetecerem.

Além disso, o mediador promoverá, nesse espaço, o contato do aluno com o livro do modo mais natural, tranquilo possível, para recebê- 
lo amistosamente na biblioteca e, principalmente, disponibilizar o material para o futuro leitor e estimulá-lo a emprestar o livro que escolheu, sem censurá-lo por um livro ter poucas páginas, por exemplo, pois ainda perdura na escola a ideia de que ser leitor é emprestar livros com muitas páginas e poucos desenhos, entretanto, o tamanho do livro não é fator determinante no processo de formação de leitores. Relevante é que o aluno se sinta acolhido de modo que suas buscas encontrem ressonância, tanto na biblioteca quanto no mediador e, ao mesmo tempo, 0 instiguem a investigar aspectos que nem sequer pensara.

A Hora do Conto é uma das atividades pedagógicas que podem ser utilizadas para incentivar a leitura nos Anos Iniciais. Essa atividade consiste em estabelecer horários semanalmente, durante as aulas, para que cada turma possa ouvir histórias, conversar sobre elas, pois a Hora do Conto é outro componente que instiga o aluno a conhecer novas histórias, novos autores e, principalmente, porque enquanto a história diverte, estimula sua imaginação e fantasia, estará favorecendo o desenvolvimento de sua personalidade (BETTELHEIM, 1985, p. 20).

Para ilustrar o que vimos dizendo, lembramos que a Hora do Conto é momento do aluno fruir o texto ouvido, saborear as palavras. É o espaço de promoção do encontro do leitor com palavras conhecidas, desconhecidas, intrigantes, assustadoras, alegres e, principalmente, sonoras. Enfim, é o momento de encantar a criança pela palavra. No entanto, na escola as histórias ouvidas pelos alunos, quase sempre, são transformadas em extensão das atividades didáticas utilizadas nas disciplinas de português e artes. Dessa forma, o sentido estético fica subjugado a atividades didáticas, escolarizantes tais como: desenhar, pintar, fazer dobraduras, reescrever a história ouvida, dar outro título para a história, entre outros aspectos, conforme Soares (1999, p. 21-22) pondera: 
tem se realizado, no quotidiano da escola. Ou seja: o que se pode criticar, o que se deve negar não e a escolarização da literatura, mas a inadequada e errônea, a imprópria escolarização da literatura, que se traduz em sua deturpação, falsificação, distorção, como resultado de uma pedagogização ou uma didatização mal compreendidas que, ao transformar o literário em escolar, desfigura-o, desvirtua-o, falseia-o.

A história de um livro, lida para a criança, deve soar em sua mente e em seu coração de modo que estimule sua imaginação e, portanto, contribua para sua compreensão de si própria e do mundo que a rodeia, enfim para o seu amadurecimento psicológico. Portanto, a história condensa força em si mesma, o que ela estimula ou provoca na criança nem sempre é visível de imediato, pois a contribuição vem num processo longo, contínuo, em cada período da vida.

$\mathrm{Na}$ escola, direta ou indiretamente, toda a equipe de ensino é mediadora de leitura, portanto, formadora de leitores, entretanto, se pensarmos no professor que, mais diretamente, terá essa tarefa, é importante elencar alguns parâmetros que possam servir para balizar as discussões.

O mediador, em princípio, deve ser leitor. E não apenas um adulto que fala da leitura para o aluno de forma discursiva, como uma atividade capaz de proporcionar prazer e conhecimento. Para alunos dos Anos Iniciais faz-se necessário levá-los a experimentar a leitura, a vivenciá-la na rotina da escola, na vida, caso contrário, será discurso pouco convincente, uma vez que essa faixa etária precisa vivenciar as atividades e transpor o nível do abstrato.

Da vivência pessoal como leitor em consonância à fundamentação teórica, surgirá o mediador habilitado para estabelecer estratégias de fomento à leitura; estimulador do ler por ler; tornar-se-á uma das fontes de sugestão de leitura para os alunos, poderá ler para eles e, também, ouvi-los ler. Importa que no processo de formação de leitor o aluno não seja encarado apenas como um sujeito passivo que receberá mensagem do livro, do professor. Ao invés disso, deve ser 
incentivado a falar sobre o que leu, discutir, compartilhar, argumentar com professor e colegas.

Caberá ao mediador compreender a formação de leitores como um processo constante na escola e na vida e que, portanto, deve ser generoso com aquele que inicia essa jornada, apoiando-o, incentivando a escolher suas próprias leituras sem criticá-lo e, ao mesmo tempo, oferecer possibilidade para que encontre novos textos.

\section{CONSIDERAÇÕES FINAIS}

A melhoria da educação do Brasil passa, dentre outros aspectos, pelo contínuo acesso da população à leitura, tanto de textos informacionais, científicos quanto dos textos artísticos. O contato diário com livros e demais suportes de leitura estimulará cada vez mais a formação de leitores e, portanto, haverá maior probabilidade de chegarmos, em menor tempo, à qualidade esperada.

Formar leitores tem sido uma das metas da educação, em especial, nos últimos 30 anos. Ainda que a escola seja considerada, em muitos países, mais uma das possibilidades nesse processo formativo, no Brasil ainda é o principal veículo de promoção da leitura em larga escala, embora falte amadurecimento pedagógico para a estruturação de uma proposta nacional que dê consecução ao propósito de formar leitores.

Da compreensão do que se deve fazer à prática cotidiana existe um trajeto que precisa ser percorrido a fim de se estabelecer procedimentos e práticas que, em conjunto, contribuam para formar leitores na escola, dentre eles, destacamos o papel da biblioteca na instituição de ensino e na formação dos alunos. Esse papel fica destituído de sentido pedagógico quando a escola possui biblioteca, mas ela não funciona, os alunos não têm acesso ao acervo, não podem manuseá-lo ou emprestá-lo. 
Escola e biblioteca, em nosso país, ainda são duas instituições com pouca relação pedagógica na escola de Anos Iniciais. Quando está presente no ambiente escolar, é como se a biblioteca fosse um corpo à parte, sem entrosamento pedagógico com o projeto de ensino, com a formação diária de alunos e professores. Assim, o afastamento entre essas instituições reflete algo mais sério, ou seja, a biblioteca está fora da discussão pedagógica escolar e, possivelmente, quem sofrerá os efeitos disso serão os alunos e, consequentemente, a sociedade.

Ausência da biblioteca nas aulas, tanto de alunos quanto de professores na escola, denota a pouca intimidade com essa instituição e com a própria leitura. Assim, se a leitura não está chegando aos alunos é provável que, também, para o grupo docente ela não fez e nem faz parte de sua vida, particular e acadêmica. Isso tudo pode ser o sintoma de algo mais grave, ou seja, os professores também não são leitores e nem têm o hábito de frequentar a biblioteca, muito menos de inseri-la como um dos recursos para suas aulas.

À escola cabe compreender que não se formam leitores sem planejamento de ações conjuntas no ambiente escolar, utilizando-se de todos os recursos materiais e humanos, visando à promoção da leitura. É preciso entender que não existe fórmula mágica para isso, mas que os resultados só virão se houver planejamento de ações objetivas, aplicação do planejamento e continuidade no processo.

O projeto de formação de leitores da escola consiste numa conjuntura de procedimentos e ações pedagógicas, realizados em concomitância, de modo que equipe de ensino empreenda ações pedagógicas que promovam o contato cotidiano com a leitura, com o empréstimo de livros, com momentos de ouvir histórias e conversar sobre elas; com o uso orientado e/ou espontâneo da biblioteca pelos alunos, enfim, cumpre à escola promover um ambiente leitor. 
A partir da continuidade e consistência de ações de leitura, desde os Anos Iniciais da escolaridade, é que se poderá assegurar que o aluno, ao chegar à graduação, seja leitor e, desse modo, possa aprofundar suas leituras, cotejar textos mais complexos e ampliar sua compreensão leitora, aprender mais.

\section{REFERÊNCIAS}

BETTELHEIM, Bruno. A psicanálise dos contos de fadas. São Paulo: Paz e Terra, 1985.

BLOOM, Harold. Como e por que ler. Rio de Janeiro: Objetiva, 2001.

BRASIL. Lei n. 12.244 de 24 de maio de 2010. Dispõe sobre a Universalização das Bibliotecas nas Instituições de Ensino no País. Disponível em: <http://www.planalto.gov.br/ccivil_03/_Ato20012010/2010/Lei/12244.htm >. Acesso em: 5 ago. 2012.

COELHO, Nelly Novaes. Literatura infantil: teoria, análise, didática. São Paulo: Moderna, 2000.

COLOMER, Teresa; CAMPS, Anna. Ensinar a ler, ensinar a compreender. Porto Alegre: ArtMed, 2002.

LAJOLO, Marisa. Do mundo da leitura para a leitura do mundo. São Paulo: Ática, 1994.

LAJOLO, Marisa. O texto não é pretexto. In: ZILBERMAN, Regina (Org.). Leitura em crise na escola: as alternativas do professor. Porto Alegre: Mercado Aberto,1986. p. 51-52.

MACEDO, Neusa Dias de. Biblioteca escolar brasileira em debate: da memória profissional a um fórum virtual. São Paulo: Senac, 2005.

ORGANIZAÇÃO DOS ESTADOS LIBERO-AMERICANOS. Avaliação das bibliotecas escolares no Brasil. 2011. Disponível em: <http://www.oei.es/noticias/spip.php?article9314>. Acesso em: 20 jul. 2012.

SILVA, Rovilson José da. Biblioteca escolar e a formação de leitores: a importância do mediador de leitura. Londrina: Eduel, 2010. 
SILVA, Rovilson José da. Formar leitores na escola. In: SILVA, Rovilson José da; BORTOLIN, Sueli. Fazeres cotidianos na biblioteca escolar. São Paulo: Polis, 2006. p. 170-171.

SOARES, Magda. A escolarização da literatura infantil e juvenil. In: EVANGELISTA, Aracy Alves Martins et al. A escolarização da leitura literária: o jogo do livro infantil e juvenil. Belo Horizonte: Autêntica, 1999. p. 21-22.

\section{Title}

Training readers at school: the educational project, the school library and the mediation

\section{Abstract}

Introduction: Discusses the formation of readers in the first years of elementary school and proposes the integration between the school pedagogical project, teachers, reading practices and the school library.

Objective: To analyze the basic assumptions to train readers in school.

Methods: Bibliographic research based on a literature review on the subject.

Results: Initial elements that may be used to structure readers-training projects at any schools are presented.

Conclusion: Training readers at school consists in having procedures and pedagogical actions performed in combination with guided and free usage of the library, borrowing books and time to hear stories and talk about them.

Keywords: Readers training in the first years of school. Reading Mediator. School Library..

\section{Titulo}

Formar lectores en la escuela: el proyecto pedagógico de aula, la biblioteca y la mediación

\section{Resumen}

Introducción: Presenta la formación de lectores en la escuela de los Anos Iniciales de la enseñanza primaria y propone la integración entre el proyecto pedagógico escolar, el grupo docente, las practicas de lectura y la biblioteca de la escuela.

Objetivo: Análisis de las premisas básicas para la formación de lectores en la escuela.

Metodología: Investigación bibliográfica, con base en la revisión de literatura a respecto del asunto. 
Rovilson José da Silva

Formar leitores na escola: o projeto pedagógico, a biblioteca escolar e a mediação

Resultados: Son presentados elementos iniciales que podrán auxiliar la reflexión y estructuración del proyecto de formación de lectores en cualquier escuela.

Conclusión: Formar lectores en la escuela consiste en una coyuntura de procedimientos y acciones pedagógicas, realizados en concomitancia, entre el uso orientado y libre de la biblioteca, el préstamo de libros y momentos de oír historias y hablar.

Palabra clave: Formación de lectores en la educación primaria. Mediador de lectura. Biblioteca escolar.

Recebido em: 07/07/2014

Aceito em: 01/05/2015 